\title{
A metaforização da mulher no Apocalipse de João
}

\section{The metaphorization of women in the Apocalypse of John}

\section{La metaforización de la mujer en el Apocalipsis de Juan}

\author{
Prof. Me. Denilson Silva Matos* \\ Submetido em: 15-1-2021 \\ Aceito em: 15-4-2021
}

\author{
* Universidade Metodista de São Paulo \\ Doutorando em Ciências da Religião pela \\ Universidade Metodista de São Paulo \\ smdenilson@gmail.com
}

\begin{abstract}
RESUMO
O mal é inquietante. Sua presença é tão incômoda que motivou os mais importantes autores clássicos a escrever sobre ele. Desde os Mitos antigos à literatura moderna, o mal é tema e, também, dilema, aporia. Uma tentativa, entre muitas, de resolver o problema do mal encontra-se na visão de mundo apocalíptica judaico-cristã. Dentre os diversos textos que surgiram desta perspectiva apocalíptica, o Apocalipse de João é o mais famoso e conhecido, devido à sua presença no cânon bíblico, texto que moldou o imaginário Ocidental. Nesse artigo buscaremos identificar como João estrutura seu texto apocalíptico e como lida com a questão do mal por meio da metaforização das mulheres.

Palavras-chave: Apocalíptica; Apocalipse de João; metáfora conceitual; mulheres.
\end{abstract}

\begin{abstract}
Evil is unsettling. Its presence is so uncomfortable that it motivated the most important classical authors to write about. From ancient Myths to modern literature, evil is a theme, and also a dilemma, aporia. One attempt, among many, to solve the problem of evil is to be found in the Judeo-Christian apocalyptic worldview. Among the various texts that emerged from this apocalyptic perspective, the Apocalypse of John is the most famous and well-known due to its presence in the biblical canon, a text that shaped the Western imagination. In this article we will try to identify how John structures his apocalyptic text and how he deals with the question of evil through the metaphorization of women.
\end{abstract}

Keywords: Apocalyptic; Revelation; conceptual metaphor; women.

\section{RESUMEN}

El mal es inquietante. Su presencia es tan incómoda que motivó a escribir sobre los autores clásicos más importantes. Desde los mitos antiguos hasta la literatura moderna, el mal es un tema y también un dilema, la aporía. Un intento, entre muchos, de resolver el problema del mal se encuentra en la cosmovisión apocalíptica judeocristiana. Entre los diversos textos que surgieron de esta perspectiva apocalíptica, el Apocalipsis de Juan es el más famoso y conocido por su presencia en el canon bíblico, texto que dio forma al imaginario occidental. En este artículo intentaremos identificar cómo João estructura su texto apocalíptico y cómo aborda la cuestión del mal a través de la metaforización de las mujeres.

Palabras clave: Apocalíptico; Apocalipsis de Juan; metáfora conceptual; mujer. 


\section{Metáfora conceitual}

Durante alguns séculos, a metáfora esteve ligada à poesia, sendo considerada distinta da linguagem comum. Fazia-se uma distinção clara entre a linguagem poética e a linguagem comum, na qual a primeira era vista como um dom especial de alguns (os poetas) e a segunda, como a linguagem de todos. A metáfora era particular da linguagem poética e deveria ser evitada na linguagem comum. Dentro desse conceito, falar metaforicamente do "desejo" em termos de "fome" ou "sede", por exemplo, deveria fazer parte apenas da linguagem poética, literária.

Essa postura em relação à metáfora pode ser encontrada em reflexões propostas pela filosofia da linguagem, por exemplo, aquelas oferecidas por Aristóteles (384-322 a.C). O modelo de Aristóteles é conhecido como modelo da comparação. Foi ele quem cunhou o termo "Metáfora" (do grego $\mu \varepsilon \tau \alpha \varphi \circ \varrho \dot{\alpha}$, "transferência, transporte para outro lugar", composto de $\mu \varepsilon \tau \dot{\alpha}$ (meta),

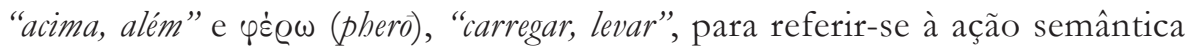
que a metáfora permite realizar, na qual o aspecto de um referente é "transitado, sobre", por assim dizer, ou transferido para outro referente, de modo que o segundo é referido como se fosse o primeiro (DANESI, 2004, p. 23).

Por exemplo, na expressão "João é um leão", estamos nos referindo à pessoa chamada "João" como se ele fosse o animal chamado "leão", para comunicar qualidades de "robustez", "força física", "vigor", "coragem”. No entanto, classificou-a substancialmente como uma estratégia retórica-ornamental, usada, sobretudo por poetas, cuja principal função foi a comparação, utilizada simplesmente para embelezar a linguagem literal.

No entanto, alguns estudiosos perceberam que a metáfora não está presente apenas na linguagem poética ou literária, ela faz parte também da linguagem comum, usada no dia a dia. As crianças reclamam de um amigo que tem muita "fome" de bola e não deixa ninguém jogar; um colega recusa o convite para ir ao cinema porque não tem o menor "apetite" para filmes de terror; um vizinho ganha na loteria sozinho, e deixa todo mundo "de água na boca".

No entanto, fazemos isso de forma tão natural e corriqueira que, em geral, nos passa despercebido (COHEN, 1979, p. 5). Até mesmo a linguagem científica, que tantos supõem ser estritamente literal, é rica em metáforas (CORACINI, 1991, p. 133), pelas quais teorias e avanços crescentes das ciências têm sido explicados. Certas áreas, como a música e a arte, não podem ser discutidas a não ser através de termos metafóricos, como "austero", "equilibrado", "gracioso", “suave”, “forte”, “quente”, “doce”, “insípido”, “fasci- 
nante", "majestoso". Nas ciências biológicas, as "células" são comumente classificadas em "idosas", "mães", "filhas", "companheiras". Na engenharia elétrica e na física, expressões do tipo "plasma faminto" e "banho de carga negativa" fazem parte de sua linguagem técnico-científica.

A partir dessa constatação, autores propuseram-se a enfrentar a corrente majoritária daquele momento, que via a metáfora como um recurso figurativo de caráter estilístico, típico de textos literários. Essa observação contribuiu para uma nova visão da mente, "metáfora passou a ser considerada como um elemento importante no processo de entendimento da própria compreensão humana, e não mais como um mero ornamento do discurso" (MACEDO; FARIAS; LIMA, 2009, p. 45). ${ }^{1}$

A partir desses esforços, surge a Teoria de Metáfora Conceitual (TMC). A teoria da metáfora conceitual surgiu em 1980, com o livro "Metaphors we live by", de George Lakoff e Mark Johnson. A partir de uma análise volumosa de dados linguísticos de diversos campos, estes autores buscam mostrar que a metáfora não é apenas um fenômeno de linguagem, mas um fenômeno de cognição que envolve a projeção de correspondências entre diferentes domínios cognitivos - um domínio-fonte, mais concreto e usualmente mais corporificado; e um domínio-alvo, mais abstrato.

Na nova perspectiva, a metáfora linguística só é possível porque existem metáforas no sistema conceitual humano, sistema que emerge de sua experiência com o próprio corpo e o ambiente físico e cultural que ele vive. Para Lakoff e Johnson, "a essência da metáfora é compreender e experienciar um tipo de coisa no lugar de outra; compreendê-la equivaleria a compreender o próprio modo de pensar e agir inerente ao homem" (1980, p. 5).

Se falamos de "desejo" em termos de "fome", por exemplo, é porque percebemos assim. Não é uma forma arbitrária ou conscientemente elaborada

\footnotetext{
Contrapondo-se a tais afirmações, o paradigma experiencialista apregoa que o significado se gera a partir das experiências de natureza sensório-motora que o indivíduo mantém com o ambiente que o cerca ao longo de seu desenvolvimento cognitivo. Segundo a semântica cognitiva, o significado linguístico não é arbitrário, porque decorre de esquemas sensório-motores internalizados a partir de nossas experiências corpóreas com o mundo. A criança, ao longo de seu desenvolvimento, nas suas interações com seu próprio corpo, com objetos e com o outro, aprende diferentes tipos de esquemas imagético-cinestésicos, como, por exemplo, o esquema de caminho, envolvendo deslocamentos de um lugar para outro: "Fui da sala para o quarto"; o esquema de recipiente, que se refere ao conhecimento de se estar dentro ou fora de algum lugar, sendo certamente o próprio corpo o fator mais saliente, neste tipo de esquema: "Nasci em Fortaleza"; e o esquema de balanço, decorrente de nossas tentativas para ficar em pé: "Ela é uma pessoa equilibrada”, entre outros. São esses esquemas internalizados que, segundo os proponentes da visão experiencialista, estruturam nossos conceitos linguísticos que se manifestam em formas gramaticais como preposições, conjunções, morfemas, tempo e aspecto verbal etc.
} 
no momento da elocução, mas, ao contrário, devido à metáfora conceitual subjacente DESEJAR É TER FOME, que é natural, automática, e, de modo geral, inconsciente.

\section{Metáforas estruturais}

Na linguística cognitiva, a metáfora é definida como a compreensão de um domínio conceitual em termos de outro domínio conceitual (KÖVECSES, 2010, p. 4). De forma abreviada: Um domínio conceitual A é o domínio conceitual B; Metáforas Estruturais. O domínio conceitual que utilizamos para entender o outro domínio conceitual é chamado de "Domínio Fonte". O domínio conceitual que tentamos entender por meio do uso do domínio de origem é chamado de "Domínio Alvo". As palavras ou expressões linguísticas que derivam do Domínio Fonte são chamados de "Expressões Metafóricas Linguísticas”.

Exemplos disto incluem o falar e pensar sobre a vida em termos de jornadas; sobre argumentos em termos de guerra; sobre amor também em termos de jornadas; sobre teorias em termos de edifícios; sobre ideias em termos de comida; sobre organizações sociais em termos de plantas e muitos outros. Exemplos:

\section{A VIDA É UMA JORNADA}

"Ele está sem direção na vida"; "Eu estou onde quero estar na vida"; "Eu estou em uma encruzilhada na minha vida"; "Ele nunca deixa ninguém entrar no seu caminho"; "Ela passou por muita coisa na vida".

\section{TEMPO É DINHEIRO}

"Você está desperdiçando meu tempo"; "Você está me fazendo perder tempo"; "Eu não tenho tempo para te dar"; "Eu não tenho tempo para você"; "Como você gasta seu tempo hoje em dia"; "Como você usa o seu tempo hoje em dia?"; "Aquele pneu furado me custou uma hora"; "Tenho investido muito tempo nela"; "Eu não tenho tempo para perder com isto"; "O seu tempo está se esgotando"; "Você não usa seu tempo lucrativamente"; "Você não aproveita bem o seu tempo".

Tempo, em nossa cultura é um bem valioso; o conceito que se desenvolveu na cultura ocidental associa o trabalho ao tempo que ele toma; paga-se as pessoas pela hora, semana, mês ou ano. Logo, compreendemos o tempo como algo que pode ser gasto, desperdiçado, orçado, bem ou mal investido, poupado etc. 


\section{Metáforas orientacionais}

Até agora examinamos o que chamamos de metáforas estruturais, ou seja, casos nos quais um conceito é estruturado metaforicamente em termos de outro. Porém, existe outro tipo de conceito metafórico que cumpre a função de organizar um sistema de conceitos em relação a outro. Esses conceitos são nomeados por Lakoff e Johnson como metáforas orientacionais (LAKOFF, JOHNSON, 2002, p. 59).

Tais metáforas correspondem às orientações espaciais do tipo: para cima - para baixo; dentro - fora; frente - atrás; em cima de - fora de; fundo - raso; central - periférico. As metáforas orientacionais dão a um conceito uma orientação espacial, pois surgem do fato de termos os corpos que temos e de como eles funcionam no nosso ambiente físico. Tais orientações têm uma base na nossa experiência física e cultural. Por exemplo:

\section{FELIZ É PARA CIMA; TRISTE É PARA BAIXO}

"Estou me sentindo para cima"; "aquilo levantou meu moral"; "meu astral subiu"; "você está de alto astral"; "pensar nela sempre me levanta o ânimo"; "estou me sentindo para baixo"; "estou deprimido"; "Ele está mesmo para baixo estes dias"; "eu caí em depressão"; "meu ânimo afundou”; "estou no fundo do poço".

Base física: Postura caída corresponde a tristeza e depressão, postura ereta corresponde a um estado emocional positivo. CONSCIENTE É PARA CIMA; INCONSCIENTE É PARA BAIXO.

"Levante-se"; "eu já estou de pê"; "ele se levanta cedo"; "ele cain no sono"; "ele está sob efeito de hipnose"; "ele cain em coma profundo".

Destacaremos algumas conclusões de Lakoff e Johnson (2002, p. 65-67) a respeito das metáforas orientacionais:

A maior parte dos nossos conceitos fundamentais são organizados em termos de uma ou mais metáforas de espacialização;

Metáforas de espacialização estão enraizadas na experiência física e cultural; elas não são construídas ao acaso. Uma metáfora pode servir como um veículo para a compreensão de um conceito apenas em função de sua base experiencial;

Em alguns casos, a espacialização é uma parte tão essencial do conceito que temos dificuldade em imaginar outra metáfora alternativa que pudesse estruturar o conceito;

Nossa experiência física e cultural proporciona muitas bases possíveis para as metáforas de espacialização e, por essa razão, sua escolha e sua importância relativa podem variar de cultura para cultura. 
A partir da teoria de metáfora proposta acima, buscaremos compreender o processo de metaforização das mulheres no Apocalipse de João, e como essa leitura contribui para a compreensão do livro e sua interação com seu ambiente sociocultural.

\section{Apocalipses e o Apocalipse de João}

Os apocalipses surgem no período conhecido como intertestamentário ou judaísmo do segundo templo (NOGUEIRA, 2008, p. 16). Esse período é marcado por uma transformação da visão de mundo presente nas gerações anteriores ao cativeiro babilônico, bem como o contato com os persas. Esse mundo dos profetas apocalípticos é o judaísmo que passa por um processo de helenização e Zoroastrismo.

A principal marca da nova visão de mundo é o Dualismo cósmico. O mundo está divido entre duas forças antagônicas, bem e mal, que disputam até o fim o domínio do mundo. Tais apocalipses cultivam um descrédito dos valores tradicionais, como, no caso, a obediência à Torá como elemento fundamental para livrá-los dos impérios opressores, pelo contrário, a história havia demonstrado o domínio dos Assírios, Babilônios e Persas (COLLINS, 2010, p. 55-61).

Há uma demonstração de pessimismo quanto à mudança histórica, restabelecimento do reinado de Davi e Jerusalém como Teocracia; muda-se a perspectiva: se Deus intervinha na realidade cotidiana do povo, agora, tampouco vive em Jerusalém, no santo dos santos, mas habita os céus, e suas intervenções estão reservadas para o grande dia do juízo final.

Nas narrativas apocalípticas, é latente a divisão entre humano e divino, este último estando bem distante do ser humano. O céu é compartimentalizado, bem estruturado (NOGUEIRA, 2008, p. 19). O ser humano não consegue chegar a ele sem uma mediação necessária e desde que transformações sejam feitas. O mundo está, assim, tomado por forças antagônicas e se desenrola uma árdua batalha que representa uma não-reconciliação.

A figura de Satã recebe contornos de opositor de Deus (Satanás, Belial, Diabo, Mastema) (NOGUEIRA, 2008, p. 20). O mundo é este palco da batalha entre demônios e seres angélicos. Segundo essa concepção, as forças do mal e do bem se oporão sem trégua até o desfecho final escatológico, ou seja, o tempo do fim. A história humana é compreendida, portanto, a partir desta tensão entre oponentes. A única alternativa é a ruptura, o fim, o juízo.

Os apocalipses falam do futuro, mas não somente disso. Falam também das origens (Mito). É uma releitura da história a partir da tensão entre criação e final. É uma visão de mundo: vai das causas da criação para entender o que 
deu errado até seus desenvolvimentos que se originaram do mesmo. Tudo está relacionado com o tempo primordial e, desta forma, pelos desacertos dos tempos da criação (rebelião humana e rebelião dos anjos) fica comprometido o equilíbrio da natureza, na política, na religião, na sociedade em geral (TERRA, 2019, p. 79-83).

Essa visão de mundo ganha força não apenas no período do Judaísmo do segundo templo, mas podemos encontrá-la no período neotestamentário, no Batista e em Jesus. Contudo, é no Apocalipse de João que fica latente a identificação com tal visão de mundo. Neste artigo, tomaremos como base o Apocalipse de João para identificar o problema do mal como aporia, bem como o modo pelo qual João tenta resolver tal problema, através de metáforas conceituais que identificam a figura das mulheres ao mal.

\section{A metaforização da mulher no Apocalipse de João}

Lynn R. Huber (2013, p. 1) aponta que o fato de João rotular sua narrativa como Apokalypsis ou "revelação de algo oculto", tem como objetivo persuadir sua audiência a ver juntamente com ele sua fantástica narrativa visionária. Ela aproxima o termo Apocalypsis ao anakalypsis, que aponta para o significado simbólico de levantar o véu da noiva, como exemplo do imaginário nupcial do mundo Greco-Romano antigo. Aponta para a proeminência da "Prostituta" no Apocalipse como um processo de revelação também, nesse caso temos a revelação do corpo da mulher, que era a principal característica das prostitutas. Assim: "Revelações ou Apocalipses são, em certo sentido, sobre revelar identidades".

Para entender o Apocalipse de João, bem como suas imagens femininas, precisamos conectar João ao seu ambiente sociocultural, pois o seu uso de imagens visuais e literárias de mulheres - da Bíblia Hebraica e do mundo Greco-Romano - representa uma mistura (blend) de conceitos metafóricos.

Huber (2013, p. 11) destaca a inerente natureza visual do Apocalipse e sua habilidade de estimular a imaginação visual. Isso não é acidental, conforme Huber: "A narrativa utiliza visualização retórica e uma estrutura literária que estimula a audiência do texto para ver o imaginário do texto juntamente com João. É seu objetivo retórico".

A tática retórica está ligada à Metáfora, ou seja, João encoraja a ver uma coisa por intermédio de outra, com o objetivo de moldar o pensamento e a ação de sua audiência. O livro do Apocalipse privilegia a visão; Deus faz conhecida a vontade divina através de imagens.

Apesar de privilegiar a visão, a fronteira entre visão e audição é borrada (blur), pois, no Apocalipse, ouvir leva a ver (4.1; 5.5-6; 6.1-2; 7.4, 9; 9.1; 21.9- 
10), ou serve para explicar o que é visto (12.10-12; 14.1-2); há uma ênfase no uso do imperativo عĩ̃ovৎ (Veja!), ressaltando o propósito retórico do texto.

João usa a linguagem da visão que corresponde às antigas técnicas de retórica da ekphrasis (a arte de usar uma linguagem para fazer algo visível diante dos olhos de uma audiência). Em certo sentido, a própria introdução do Apocalipse sinaliza que o texto como um todo serve como uma ekphrasis on demonstratio estendida.

A linguagem sensorial que o visionário utiliza para recontar suas experiências. Eles descrevem o que veem, ouvem e experimentam. Essa linguagem torna a literatura apocalíptica um poderoso método de persuasão. Um texto visionário permite a audiência a ver "by proxy", através dos olhos do vidente. É retórica. Se a audiência vê o que João vê, conhecerão como ele conhece e acreditarão como ele acredita. Ressalta, também, o uso saturado de símile e metáfora no texto.

João utiliza o adjetivo ő $\mu$ oı mais de 50 vezes. Ele se baseia em coisas que a audiência conhece, como locustas e cavalos, para evocar coisas que eles não experienciaram, como as bestas do abismo. Huber ressalta a importância da metáfora no seu contexto retórico e sua inadequação para a apropriação moderna. A tarefa do intérprete é explorar como o texto usa a metáfora e imaginário para criar um universo simbólico no qual a audiência é convidada a participar. Através da metáfora, uma audiência pode ser estimulada a ver coisas de uma maneira particular, da perspectiva do orador.

Huber (2013, p.35) aprofunda o imaginário visual feminino no mundo Greco-Romano e no Apocalipse. Seu primeiro exemplo é o Ara Pacis Augustae, dedicado em 9 a.C e construído para comemorar o triunfo de Augusto na Espanha e na Gália, localizado no Campus Martius junto a Via Flaminia. O monumento está envolto em frisos com representações da família imperial e dignitários em procissão sagrada, além de frisos que representam o passado mítico de Roma, e duas figuras femininas. Esse imaginário, que ela chama de "mitologia romana", satura o mundo do Apocalipse e molda a visão de João. Retoricamente, João tenta alcançar seu objetivo criando um sentido de inimizade com o poder dominante de seu tempo. Essa tática inclui a utilização de imaginário metafórico.

Por exemplo, PODERES TERRESTRES SÃO BESTAS (Livro de Daniel). João incita sua audiência a imaginar uma besta estranha, a fim de que eles entendam o reinado terrestre como ameaçador. O Apocalipse também usa o imaginário metafórico para criar uma identidade comunal positiva: OS FIÉIS SÃO A NOVA JERUSALÉM. 
Como sublinhado anteriormente, o altar de Augusto inclui imagens de mulheres apontando para o papel simbólico da materfamilias, sublinhando a importância do casamento e da maternidade, especialmente dentro das classes altas. Esse imaginário foi utilizado para organizar como alguém deveria pensar acerca de coisas, cidades, países e grupos de pessoas. Em toda parte do império, os grupos dominados são representados como mulheres. UMA NAÇÃO É UMA MULHER. UMA MULHER É UM CONTAINER. A conquista é vista como penetração sexual/estupro. CONQUISTA É PENETRAÇÃO SEXUAL. Essas metáforas indicam, necessariamente, o que deve acontecer com essas nações dominadas, visto que o gênero feminino e o corpo feminino eram designados para a penetração e dominação.

O corpo feminino representa UMA NAÇÃO no contexto Romano, mulheres foram usadas como representação metonímica de Roma. As virgens Vestais, sacerdotisas da deusa Vesta, eram tomadas de suas famílias e passavam a viver no Fórum Romano como sacerdotisas, cuidando do fogo sagrado de Vesta. A CONDIÇÃO MORAL DE UMA CIDADE É A CONDIÇÃO MORAL DE UMA MULHER.

A tradição profética também fornece muitas fontes para a narrativa visionária de João, principalmente a representação de uma cidade ou comunidade como mulher, JERUSALÉM É UMA ESPOSA e DEUS É UM MARIDO.

João se utiliza de metáforas tradicionais para engajar sua audiência criando uma "contra-mitologia". Uma resistência simbólica, a constante "revelação" do corpo da mulher demonstra, de forma estereotipada, que mulheres são propensas à promiscuidade (Ez 16.39-40; Os 2.10). O domínio conceitual MULHER, como atestado anteriormente, aparece metaforicamente em conjunto com terras, nações, cidades e grupos de pessoas. UM ESPAÇO É UMA MULHER, UMA TERRA É UMA MULHER, UMA NAÇÃO É UMA MULHER. UMA MULHER É UM CONTAINER. UMA MULHER É UMA CIDADE.

Na primeira metade do livro do Apocalipse, há um domínio dos personagens masculinos, contudo, a partir do capítulo 12, aparecem as mulheres proeminentes no texto: A mulher vestida de Sol, A Noiva do Cordeiro, e a Grande Prostituta. Essas mulheres "são retoricamente proeminentes, são fantasiadas, criticadas, protegidas e resgatadas, demonizadas e destruídas e aperfeiçoadas" (HUBER, 2013, p. 57). Contudo, as imagens femininas podem e apontam para coisas e ideias além delas mesmas.

Ao apresentar o capítulo 17, João evoca o tropo retórico da ekprhasis, sublinhando que a Prostituta é algo que a audiência precisa ver. Essa prostituta não é uma cortesã, ela é descrita como uma prostituta de bordel, e 
o nome em sua testa evoca o escravo sexual tatuado do comércio romano. A partir do mapeamento conceitual, UMA CIDADE É UMA MULHER, associa Roma com a Babilônia a partir das referências da Bíblia Hebraica e de escritos judaicos do primeiro século, tais como 4 Esdras e 2 Baruque.

João, ao representar a cidade como uma Prostituta, sublinha sua infamis. Faz com objetivo de cultivar um sentido de inimizade com a grande cidade. Mesmo que a imagem da Grande Prostituta funcione, primeiramente, como uma condenação de Roma, incluindo seu poder e seu desejo por luxúria, essa imagem é utilizada, num segundo momento, para moldar a identidade e as ações das comunidades de cristãos a quem João se dirige. Ao representar Roma como uma mulher, especificamente como uma Prostituta, em termos de violação e destruição, João toca no que alguns podem imaginar como reconfortante (Paz Romana e poder) e tenta transtornar sua audiência: A cidade como Prostituta não é um lugar seguro.

\section{Conclusão}

Enquanto nós não podemos despir o Apocalipse de seus paradigmas patriarcais, podemos entender como o autor usa-os e como eles moldam a imaginação dos intérpretes do Apocalipse. Contudo, não há como negar a culpabilização/cooperação da mulher com o mal. Seu objetivo é convencer sua audiência que "A Grande Babilônia" é a personificação da Besta, Diabo, Mastema, Serpente, Dragão, do Mal, e a imagem metafórica presente no imaginário de João é aquela das mulheres como cooperadoras do mal, de Gênesis, de Enoque e dos profetas veterotestamentários. Contudo, como atesta Magalhães (2012, p.140), os personagens bíblicos não estão isentos de mutabilidade, tampouco Deus, que no Apocalipse é terrivelmente bom e mal, constrói e destrói, ama e condena. Aqui, cabem as palavras de José Saramago (1991, p. 242):

[...] e olha que se encontrássemos o Diabo e ele deixasse que o abríssemos, talvez tivéssemos a surpresa de ver saltar Deus lá de dentro. [...] podia ter sido bem pior, imagine-se o escândalo se Pastor se lembrava de abrir Deus para ver se o Diabo lá estava dentro.

\section{Referências bibliográficas}

CHARLESWORTH, James H. The Old Testament Pseudepigrapha. Vol. 2: Expansions of the "Old Testament" and legends, wisdom and philosophical literature, prayers, psalms, and odes, fragments of lost Judeo-Hellenistic works. New York: Doubleday. 1985. 
COLLINS, John J. A imaginação apocalíptica: uma introdução à literatura apocalíptica judaica. São Paulo: Paulus, 2010.

CROATTO, Severino J. As linguagens da experiência religiosa: uma introdução à fenomenologia da religião. São Paulo: Paulinas, 2001.

DANESI, Marcel. Metáfora, pensamiento y lenguaje: una perspectiva viquiana de teorización sobre la metáfora como elemento de interconexión. Sevilla: Kronos, 2004.

ELIADE, Mircea. Mito e realidade. São Paulo: Perspectiva, 1972.

FRYE, Northrop. O Código dos Códigos: a Bíblia e a literatura. São Paulo: Boitempo, 2004.

HUBER, Lynn. Thinking and seeing with women in Revelation. (The Library of New Testament Studies). London: T\&T Clark, 2013.

KÖVECSES, Zoltan. Methaphor: a practical introduction. London: Oxford University Press, 2010.

LAKOFF, George; JOHNSON, Mark. Metaphors we live by. Chicago: University of Chicago Press, 1980.

LAKOFF, George; JOHNSON, Mark. Metáforas da vida cotidiana. Trad. Mara Sophia Zanottoe Vera Maluf. São Paulo: EDUC; Mercado Letras, 2002.

MACEDO, Ana Cristina P. S. de; FARIAS, Emilia M. Peixoto; LIMA, Paula L. Costa. Metáfora, cognição e cultura. Gragoatá, Niterói, v. 14, n. 26, p. 43-60, 2009.

MAGALHAES, Antônio Carlos de Melo. A Bíblia na crítica literária recente. Teoliterária, v. 2, n. 4, p. 133-143, 2012.

MIELIETINSKI, E. M. A poética do Mito. Rio de Janeiro: Forense Universitária, 1987.

NOGUEIRA, Paulo Augusto de Souza. O que é Apocalipse. São Paulo: Brasiliense, 2008.

NOGUEIRA, Paulo Augusto de Souza. Religião de visionários: apocalíptica e misticismo no Cristianismo Primitivo. São Paulo: Loyola. 2005.

NOGUEIRA, Paulo Augusto de Souza. Experiência religiosa e crítica social no cristianismo primitivo. São Paulo: Paulinas, 2003.

SARAMAGO, José. O Evangelho Segundo Jesus Cristo. São Paulo: Companhia das Letras, 1991.

SEGAL, Robert A. Myth: A very short introduction. Oxford: Oxford University Press, 2004.

STRAUSS, Levi. Mito e significado. Lisboa: Edições 70, 1978.

TERRA, Kenner. O Apocalipse de João: caos, cosmos e o contradiscurso apocalíptico. São Paulo: Recriar, 2019. 